DOI: 10.5007/2175-7941.2012v29n2p207

\title{
ANÁLISE DE BIOGRAFIAS DE EINSTEIN EM DOIS LIVROS DE DIVULGAÇÃO CIENTÍFICA ${ }^{+*}$
}

Guilherme Urias

Mestrando do Programa de Pós Graduação em Educação para Ciência -

UNESP

Alice Assis

Faculdade de Engenharia de Guaratinguetá - UNESP

Guaratinguetá - SP

\section{Resumo}

Neste trabalho, propomos analisar e comparar duas biografias do fisico Albert Einstein. A primeira foi "Albert Einstein e seu universo inflável”, escrita por Mike Goldsmith, e a segunda, "Einstein: sua vida, seu universo”, escrita por Walter Isaacson. O intuito dessa comparação é o de identificar os pontos convergentes e divergentes das duas obras, além de verificar os possíveis detalhes importantes da vida de Albert Einstein que possam ter sido negligenciados com a intenção de facilitar a compreensão dos conteúdos abordados na obra de Goldsmith. Tais detalhes são aqueles que consideramos importantes no contexto do desenvolvimento intelectual de Albert Einstein, e que podem ter contribuido significativamente para a construção de suas teorias. Para tanto, fundamentamos a análise na perspectiva de Douglas Allchin, cujo trabalho apresenta aspectos na retórica de um texto que contribuem para a mitificação da ciência e do cientista.

Palavras-chave: Divulgação científica. Mitificação da ciência. Albert Einstein. Ensino de Ciências.

\footnotetext{
The analysis of Einstein's biography in two popular Science books

* Recebido: janeiro de 2012.

Aceito: junho de 2012.
}

Cad. Bras. Ens. Fís., v. 29, n. 2: p. 207-228, ago. 2012. 


\begin{abstract}
In this paper we analyzed and compared two Albert Einstein's biographies. The first one was "Albert Einstein and his inflatable universe", written by Mike Goldsmith. The second biography was "Einstein - his life and universe", written by Walter Isaacson. The intention of this comparison was to identify convergent and divergent points between two books, beyond verifying the possible neglected important points of Einstein's life suppressed by Goldsmith to facilitate the comprehension of the text. Such details are those that we consider important to Albert Einstein's intellectual development, and may have significantly contributed to the development of his theories. For this, our analysis was grounded in Douglas Allchin's perspective, whose work presents aspects in the rhetoric of the text that contribute to the Science and scientist mystification.
\end{abstract}

Keywords: Popular Science. Scientific myth-conceptions. Albert Einstein. Science Education.

\title{
I. Introdução
}

É cada vez mais comum nos depararmos com livros de divulgação científica nas prateleiras de algumas livrarias. Um dos braços que alavanca esse mercado no Brasil é o da popularização da ciência, que recebeu atenção diferenciada nos últimos anos. A forte demanda pela literatura científica viabilizou o surgimento de periódicos, programas de televisão, sítios da internet, entre outros, especializados em divulgar os acontecimentos científicos contemporâneos.

No entanto, há uma grande preocupação da comunidade acadêmica acerca da forma como esse conhecimento chega aos leitores. Normalmente, as obras dos autores de livros de divulgação científica "costumam ser acusadas de distorcer a ciência, na tentativa de apresentar algo compreensível a um público mais amplo" (MARTINS, R. A., 2008, p. 243).

Sem dúvida, a linguagem que torna o conhecimento científico acessível aos leitores não especializados se diferencia daquela utilizada pelos cientistas. Justamente por isso, o jornalista Cássio Leite Vieira (2004), editor de uma revista de divulgação científica, cuja "função é adequar conteúdo e linguagem dos originais enviados pelos cientistas para leitores não especializados" (p. 13), publicou 
um manual que contém dicas de como produzir um texto que visa à divulgação de um estudo científico, já que o material que chegava às suas mãos, em geral, era dotado de linguagem técnica, incluindo, às vezes, fórmulas complexas e jargões impenetráveis, inadequados ao público comum.

Essa reinterpretação que o jornalista faz provavelmente distorce o verdadeiro conhecimento científico. Na verdade, não só esse tipo de conhecimento, mas todo aquele que passa por filtros humanos é passível de distorção. Além disso, na tentativa de simplificar a linguagem científica, o intérprete pode deixar de lado detalhes enriquecedores do conteúdo a ser popularizado.

Gaston Bachelard (1996) identificou como o primeiro obstáculo epistemológico essa reinterpretação, que, inevitavelmente, distorce a visão real das coisas, pois o intérprete agrega ao conhecimento em questão suas concepções cotidianas:

Na formação do espirito científico, o primeiro obstáculo é a experiência primeira, a experiência colocada antes e acima da crítica - crítica esta que $e ́$, necessariamente, elemento integrante do espirito cientifico. Já que a crítica não pôde intervir de modo explícito, a experiência primeira não constitui, de forma alguma, uma base segura (p. 20).

Nesse sentido, é provável que a informação científica popular transposta na obra de divulgação não esteja de acordo, em essência, com o conhecimento da obra original, e é nessa perspectiva que, neste trabalho, nos propomos a analisar e comparar duas biografias do físico Albert Einstein.

A primeira, intitulada "Albert Einstein e seu universo inflável", escrita por Mike Goldsmith (2002), dedicada ao público infanto-juvenil, retrata a vida e obra do físico alemão de forma cômica e hilariantemente ilustrada. $\mathrm{O}$ autor até mesmo apelida o cientista de Beto, provavelmente para quebrar a formalidade associada à figura de Einstein.

Já a segunda obra a ser analisada, intitulada "Einstein: sua vida, seu universo", escrita por Walter Isaacson (2007), que tem o público adulto como alvo, por conter termos técnicos da Teoria da Relatividade, exige um grau maior de abstração e interpretação. O autor teve acesso ao acervo pessoal de Albert Einstein, que contém cartas trocadas com parentes, amigos e cientistas, além de seus diários e blocos de anotações. Esse detalhe nos levou a aferir à obra de Isaacson maior crédito, visto que utilizou fontes primárias como referências.

O intuito dessa comparação é o de identificar os pontos convergentes e divergentes das duas obras, além de verificar os possíveis detalhes importantes da vida de Albert Einstein que possam ter sido negligenciados com a intenção de facilitar a compreensão dos conteúdos abordados na obra de Goldsmith. Para tanto, 
fundamentamos a análise na perspectiva de Douglas Allchin (2003), cujo artigo afirma "que os ajustes que procuram aparentemente elevar o nível de compreensão de uma história, certamente contribuirão para a perda de alguns detalhes" ${ }^{1}$ (p. 344). Tais detalhes são aqueles que consideramos importantes no contexto do desenvolvimento intelectual de Albert Einstein, e que podem ter contribuído significativamente para a construção de suas teorias.

Iniciamos o artigo relatando a maneira como os autores dos dois livros analisados abordaram aspectos da infância de Albert Einstein. Nessa etapa da vida do cientista, alguns acontecimentos foram marcantes, como o seu primeiro contato com uma bússola e o incentivo ao estudo de ciências e matemática, recebido de pessoas que frequentavam o seu ambiente familiar. Ainda durante a infância, Einstein desenvolveu uma notável aversão à autoridade, uma característica de sua personalidade que também influenciou no desenvolvimento de suas teorias e foi determinante para que o cientista atuasse em movimentos políticos e sociais.

Na sequência do artigo, analisamos como Goldsmith e Isaacson abordaram a relação entre Mileva Maric e Einstein, além do importante papel da Academia Olímpia na formação intelectual do cientista. Selecionamos, também, o período em que Einstein trabalhou no escritório de patentes, pois, segundo os autores, foi nessa época que Albert desenvolveu uma grande capacidade de administrar o tempo e um invejável poder de concentração. Tais habilidades foram determinantes no desenvolvimento das Teorias da Relatividade, Especial e Geral.

Apesar de havermos encontrado algumas falhas acerca dos termos técnicos sobre a Teoria da Relatividade e em outras descrições de fenômenos físicos, apresentados no livro escrito por Goldsmith, vamos nos ater aos trechos que dizem respeito à vida do físico alemão. Talvez, em uma outra oportunidade, essa crítica seja feita sob a ótica da física teórica, que invariavelmente sofre distorções nesse tipo de obra.

\section{A infância de Einstein}

Ambos os livros iniciam relatando a demora que Einstein apresentou para proclamar as primeiras palavras. Isaacson evidencia um fragmento escrito pelo próprio cientista:

\footnotetext{
${ }^{1}$ As stories are shaped to heighten their apparent informativeness, certain types of details will tend to be lost.
} 
$O$ adulto comum nunca importuna a mente com problemas de espaço e tempo. Já pensou nessas coisas na infância. Mas eu me desenvolvi tão lentamente que comecei a refletir sobre espaço e tempo quando já era grande. Em consequência disso, aprofundei-me mais no problema do que uma criança comum o faria (2007, p. 29).

Goldsmith corrobora, afirmando que "alguns acham que foi por isso (lento desenvolvimento) que ele desenvolveu sua prodigiosa imaginação visual, que aplicou aos problemas científicos" (2002, p. 09). No entanto, relata que "não há nada de especial para contar sobre a infância do Beto" (Ibid.). Mas esse não é o enfoque dado por Isaacson, que relacionou o lento desenvolvimento durante a infância ao comportamento rebelde e descarado "contra a autoridade" (2007, p. 28). Essa característica de Einstein, que voltaremos a abordar mais tarde, marcou toda a sua vida, pois se declarou contrário a todo tipo de repressão, principalmente a imposta pelo militarismo, chegando ao ponto de renunciar à cidadania alemã para não se apresentar ao serviço militar obrigatório. Isaacson relata, ainda, que essa mesma característica ajudou a "torná-lo o gênio científico mais criativo dos tempos modernos, ou ao menos ele assim conjecturou, mais tarde" (2007, p. 29).

Percebemos que o enfoque dado à infância de Einstein diverge entre os autores. Para Isaacson, a infância representou um momento importante na formação da personalidade do físico, mas, para Goldsmith, não. É importante salientar que a falta de detalhes na abordagem de Goldsmith alimenta a caricatura genial de Einstein, como se o físico tivesse herdado tais características do berço. Isaacson, diferentemente, evidencia que Einstein foi criado em um ambiente ideal, em que foi incentivado a estudar: "felizmente nasceu numa família inteligente, de mentalidade independente, que valorizava o estudo, e sua vida sem dúvida foi afetada de modo admirável" (2009, p. 30).

Allchin (2003) chama de "monumentalização" o artifício utilizado por Goldsmith para apresentar Einstein como um cientista genial, inflando suas realizações, minimizando seus erros, atribuindo ao cientista uma caricatura heroica.

Essa imagem de Einstein, a de herói, está enraizada na sociedade. As pessoas acreditam que ele era um gênio desde que nasceu. Um fato que ficou marcado na história como um dos grandes feitos do menino prodígio foi o de ter questionado o funcionamento da bússola. Por isso, resolvemos avaliar essa questão nos dois livros analisados. 


\section{A bússola}

O relato dos dois autores é semelhante. Goldsmith mostra que, ao ganhar a bússola, "Beto ficou fascinado" (2002, p. 09). Da mesma forma, Isaacson mostra em um trecho dos diários de Einstein, que a bússola realmente impressionou o cientista: "ainda lembro - ou ao menos acredito lembrar - que aquela experiência provocou em mim uma impressão profunda" (2007, p. 33).

Esse acontecimento fez com que Einstein desenvolvesse "pela vida afora uma devoção pelas teorias de campo como modo de descrever a natureza" (ISAACSON, 2007 p. 33). O historiador da ciência Geraldo Holton bem verificou que Einstein via "o conceito clássico de campo como a maior contribuição ao espírito científico" (1973 apud ISAACSON, 2007 p. 33).

Já Goldsmith suprime os detalhes, encerrando o assunto sobre a bússola dizendo que "o magnetismo fascinou-o pelo resto da vida, embora o Beto nunca tenha conseguido explicar direito como isso se encaixava no Universo" (2002, p. 10). A falta de detalhes pode contribuir para a mistificação da ciência, "que, para muitos, ainda é vista como algo praticado por seres superiores e completamente isolada do contexto social em que está inserido o cientista" (URIAS; ASSIS, 2011, p. 03).

Allchin (2003) evidencia em seu trabalho que existem autores que defendem a mitificação da ciência e do cientista. Segundo o autor, em uma pesquisa realizada por Brush, em que os alunos "foram expostos ao real, à visão não mítica do cientista" (p. 342), houve uma preocupação por parte de Brush ao considerar a possibilidade de que essa abordagem tenha gerado o desinteresse desses alunos por se tornarem cientistas, em virtude das dificuldades encontradas nessa carreira, como necessidade de se possuir familiaridade com a matemática avançada, ter os sensos crítico e criativo aguçados (p. 342), a dificuldade de inserção no mercado de trabalho, entre outras.

No entanto, Allchin (2003) questiona os caminhos que a visão mítica da ciência e do cientista pode se valer para desencorajar os estudantes a seguirem na carreira científica: "Se um estudante que apresenta forte interesse pela ciência (mas talvez desprovido de habilidades) pode inferir que ele ou ela não podem produzir contribuições significativas, então por que tentar?" 2 (p. 343). Segundo o autor, essa visão apenas reforça a ideia de que a ciência foi feita para os gênios.

2 That is, a student with a keen interest in science (but perhaps unproven ability) may infer that she or he cannot make a meaningful contribution, so why try? 
Talvez, se o incentivo à ciência assumisse um patamar de importância na escola, poderíamos ter mais jovens procurando desenvolver habilidades para essa carreira, como aconteceu com Einstein, que recebeu incentivos de pessoas próximas para estudar ciências e matemática, como veremos a seguir.

\section{Incentivo às ciências}

Albert foi muito incentivado ao estudo de ciências e matemática pelo seu tio, Jakob Einstein. Como aponta Goldsmith, uma das razões do "interesse de Beto pela ciência foi seu tio Jakob, [...] foi ele quem ensinou álgebra e geometria" (2002, p.10). A obra de Isaacson corrobora essa afirmação, narrando o incentivo dado pelo tio, que "passava ao menino problemas cada vez mais difíceis" (2007, p. 36).

Segundo Isaacson, outra ilustre figura teve fundamental importância na formação científica de Einstein, o estudante de medicina Max Talmud, que lhe levava "livros de ciências, inclusive uma coleção popular ilustrada cujo título era People's books on natural science" (2007, p. 37), composta por 21 volumes. No primeiro volume, o autor desses livros, Aaron Beirstein, "pedia aos leitores que imaginassem estar num trem muito veloz" (2007, p. 38). Isaacson acredita que, por isso, essa literatura tenha exercido vital importância no desenvolvimento da habilidade de Einstein para construir experimentos mentais.

Esse detalhe mostra que Einstein parece ter sido preparado para desenvolver a Teoria da Relatividade na perspectiva de Isaacson. Na verdade, o autor parece ter essa intenção, a de mostrar que Albert foi profundamente influenciado por alguns autores, e que pôde conviver com pessoas que o incentivaram aos estudos, o que contribuiu para o desenvolvimento de uma personalidade voltada para a ciência. Allchin (2003) chama de narrativa explicativa justificativa a retórica de um autor que apresenta a ciência como uma certeza, em que uma série de resultados poderia culminar em uma descoberta científica.

Outro aspecto que Isaacson incluiu nesse rol de fatos encadeados na vida de Einstein, que influenciaram e determinaram sua personalidade, colocando-o em uma situação privilegiada para o desenvolvimento da carreira científica, foi a aversão a qualquer manifestação de autoridade que o cientista apresentou desde a infância. 


\section{Aversão à autoridade}

Além do incentivo à matemática, Talmud introduziu Einstein na filosofia; recomendou ao garoto a leitura da obra de Kant, e Einstein a compreendeu perfeitamente (GOLDSMITH, 2002; ISAACSON, 2007). Kant tornou-se o filósofo favorito de Einstein por um tempo, e sua Crítica da razão pura acabou levando-o a David Hum, Ernst Mach e à questão do que pode ser conhecido sobre a realidade. A exposição de Einstein à ciência e à filosofia "produziu nele uma súbita reação contra a religião aos doze anos" (ISAACSON, 2007, p. 39). Albert acabou por negar toda e qualquer forma de dogma e autoridade.

Essa rebeldia, para a época, é relatada nos dois livros sob aspectos similares, em que é narrada a exposição de Einstein a um desfile militar. O pequeno garoto caiu no choro, dizendo aos pais que, quando crescesse, não queria ser igual àqueles pobres coitados (GOLDSMITH, 2002; ISAACSON, 2007).

A aversão à autoridade "levou Beto a se desinteressar mais ainda pela escola, onde ele tinha de simplesmente aceitar o que lhe diziam, sem nada questionar" (GOLDSMITH, 2002 p. 17). Ele queixava-se dizendo que o sistema de ensino no ginásio de Munique assemelhava-se "muito aos métodos do exército prussiano, onde a disciplina mecânica era obtida pela execução repetida de ordens inexpressivas" (ISAACSON, 2007 p. 41).

Mais uma vez, os detalhes fazem a diferença na obra de Isaacson. Apesar de Goldsmith relatar os mesmos acontecimentos, não afere a mesma profundidade dada por Isaacson. O trecho a seguir da obra de Isaacson ilustra que a atitude rebelde de Albert se revelou mais um detalhe fundamental para o desenvolvimento da sua carreira científica. Na perspectiva do autor,

durante seis décadas de carreira científica, ou liderando a revolução quântica, ou resistindo a ela posteriormente, tal atitude ajudou a moldar a obra de Einstein. "Sua precoce desconfiança da autoridade, que jamais o abandonou completamente, mostraria ter importância decisiva", disse Banesh Hoffmann, colaborador de Einstein em anos posteriores. "Sem isso ele não teria sido capaz de desafiar as crenças científicas estabelecidas, e assim revolucionar a física (ISAACSON, 2002 p. 41)

A restrição nos detalhes, feita por Goldsmith, evidencia outro artifício enunciado por Allchin (2003), chamado idealização, que consiste em aprimorar e nivelar o enredo histórico e a descoberta científica para o público alvo. Segundo o autor, perde-se a qualidade do texto e apenas os extremos da história são enfatizados. Toda a rede histórica que caracteriza o fato científico em questão é reduzida a 
uma simples linha temporal. Dessa forma, o enredo é minimizado e são excluídas as alternativas de interpretação da personalidade do cientista, do pano de fundo biográfico, do embate científico da época, etc. Ou seja, os detalhes de tempo, lugar e cultura são tidos como secundários.

No trecho a seguir, apresentamos a forma como os autores relacionaram a figura de Mileva Maric com a carreira de Albert Einstein. É possível perceber mais alguns indícios de monumentalização e de idealização na narrativa de Goldsmith, que praticamente ignorou influência da ex-mulher do cientista.

\section{Mileva Maric}

Mileva estudou física e matemática na Politécnica de Zurique, onde conheceu Einstein. A presença de Mileva Maric na vida de Einstein foi ignorada por Goldsmith. O autor reservou duas páginas para evidenciar o casamento dos amantes e o nascimento de dois dos filhos, Lieserl e Hans Albert. Novamente, o autor valeu-se do conceito de idealização, proposto por Allchin (2003).

Já Isaacson destaca, no relacionamento de Maric e Einstein, alguns aspectos que foram fundamentais para o desenvolvimento das teorias einsteinianas.

Existe uma controvérsia a respeito do verdadeiro papel de Mileva Maric no desenvolvimento da teoria da Relatividade Especial. Isaacson reproduziu trechos de cartas em que Maric narrava a sua participação no desenvolvimento da teoria: "não faz muito tempo, terminamos um trabalho muito significativo, que tornará meu marido famoso mundialmente" (ISAACSON, 2007, p. 152). Einstein também deu indícios da colaboração de Mileva: "Preciso da minha mulher. Ela resolve todos os problemas matemáticos para mim" (Ibid.); e, em uma carta à esposa: "como ficarei feliz e orgulhoso quando nós dois, juntos, chegarmos a uma conclusão para nosso trabalho sobre o movimento relativo" (Ibid.).

Algumas conferências já foram feitas na tentativa de atribuir o devido crédito à Mileva Maric. Segundo Issacson (2007), há quem diga que o primeiro esboço do artigo da Relatividade Especial continha o nome da companheira como coautora. Porém, esse boato foi desacreditado. Isaacson registra, ainda, que o filho do casal, Hans, relatou que "Mileva o ajudou a resolver alguns problemas matemáticos, mas ninguém poderia colaborar em seu trabalho criativo, no fluxo de ideias" (ISAACSON, 2007, p. 153).

Sem dúvida, Mileva teve importância fundamental no trabalho de Einstein, seja por ter contribuído com a resolução de problemas matemáticos, ou encorajando o marido e, até mesmo, aturando-o, o que, em alguns momentos, foi o mais difícil (ISAACSON, 2007). 
Outras personalidades também desempenharam vital importância para o desenvolvimento intelectual de Einstein, como os colegas que frequentavam a Academia Olímpia.

\section{A Academia Olímpia}

Goldsmith inicia hilariamente o relato dos encontros entre Maurice Solevine, Conrad Habicht e Albert Einstein:

Academia Olimpia. Condições de adesão: 1) Ser um gênio; 2) Chamar-se Maurice, Conrad ou Beto; 3) Gostar de ouvir o Beto tocar violino; 4) Ler pelo menos um livro bem grosso por semana; 5) Gostar de física, filosofia e literatura; 6) Gostar de beber; 7) Falar alto no bar (GOLDSMITH, 2002, p. 54).

Como em outros trechos do livro, a idealização de Allchin (2003) é constatada novamente. O autor apenas menciona a Academia Olímpia, relatando como foi criada, suprimindo, na nossa perspectiva, uma etapa muito importante na formação intelectual de Einstein, em que teve acesso à literaturas que contribuíram para aguçar ainda mais o seu senso crítico.

Foi na Academia Olímpia que Albert teve acesso à David Hume, com seu Tratado da Natureza Humana; Ética, de Baruch Espinosa; Análise das sensações e A mecânica e seu desenvolvimento, de Ernst Mach; e Ciência e hipótese, de Henri Poincaré (ISAACSON, 2007).

David Hume exerceu grande influência no pensamento de Einstein. O filósofo "era cético acerca de qualquer conhecimento diferente daquele que podia ser percebido diretamente pelos sentidos" (ISAACSON, 2007, p. 99). Foi por isso que Hume "aplicou seu rigoroso ceticismo ao conceito de tempo" (p. 100). Para o filósofo, não fazia sentido "falar do tempo como se tivesse existência absoluta, independente de objetos observáveis cujos movimentos nos permitiam definir o tempo" (Ibid.). "Essa ideia de que não havia algo como o tempo absoluto ecoaria mais tarde na teoria da relatividade de Einstein" (Ibid.).

O empirismo de Hume levou Einstein à leitura das obras de Mach, que se tornaram as leituras preferidas da Academia. Essas obras ajudaram a "instilar em Einstein o ceticismo quanto ao conhecimento recebido e às convenções aceitas, que viria a ser o marco de sua criatividade" (ISAACSON, 2007, p. 101). Isaacson faz uma descrição da filosofia de Mach e evidencia o ponto de influência fundamental na Teoria da Relatividade Especial: 
Para um conceito fazer sentido, é necessária uma definição operacional dele, uma que descreva como se observaria esse conceito em operação. Isso seria frutuoso para Einstein quando, alguns anos depois, ele e Besso discutissem qual observação daria significado ao conceito aparentemente simples de dois eventos ocorrerem "simultaneamente" (2007, p. 101).

Outro autor que influenciou profundamente os integrantes da Academia Olímpia foi Baruch Espinosa. Einstein herdou desse autor a "fé no determinismo: um senso de que as leis da natureza, quando conseguimos identificá-las, determinam causas e efeitos imutáveis, e de que Deus não joga dados permitindo que os eventos sejam aleatórios ou indeterminados" (ISAACSON, 2007, p. 102). A concepção determinista faria com que Einstein refutasse categoricamente a teoria quântica, que, paradoxalmente, ajudou a construir.

Assim, depois de muitas leituras na Academia Olímpia, Einstein adquiriu um conhecimento filosófico ímpar, que despertaram sua criticidade e o levaram a questionar o tempo e a realidade. Quando conseguiu um trabalho no escritório de patentes, pôde desenvolver mais algumas habilidades e, também, iniciar o esboço de suas teorias.

\section{O escritório de patentes}

O trabalho no escritório de patentes surgiu num momento difícil da vida de Einstein. Todas as tentativas de engrenar na carreira acadêmica haviam sido refutadas (GOLDSMITH, 2002; ISAACSON, 2007). O amigo Marcel Grossmann conhecia o diretor do escritório e, por isso, colocou exigências no edital da concorrência para favorecer Albert. Dessa forma, Einstein já sabia que seria empregado antes mesmo do anúncio ser feito (ISAACSON, 2007).

Goldsmith ilustra de forma cômica como Einstein se relacionava com o trabalho. Não é difícil de perceber o efeito da monumentalização no texto, em que a personalidade do cientista "emana virtudes"3 (ALLCHIN, 2003, p. 342). Na perspectiva do autor, Einstein declararia:

Enfim consegui um bom emprego no Serviço de Patentes: só oito horas por dia, seis dias por semana. Além disso, dou aulas particulares - uma ou duas por dia -, vou às reuniões da Academia Olímpia e faço leituras para eles. Assim, tenho tempo de sobra para descobrir o significado do Universo (no

\footnotetext{
3 exudes virtue
} 
momento, estou me dedicando a tempo, partículas luminosas, átomos e estatística). Portanto, o único problema é o que fazer com o meu tempo livre (GOLDSMITH, 2002, p. 55).

Já Isaacson apresenta trechos de uma carta que Einstein escreveu a um amigo, dizendo: "estou terrivelmente ocupado [...]; passo oito horas por dia no escritório, dou pelo menos uma hora de aula particular e depois ainda faço algum trabalho científico" (2007, p. 96).

Acreditamos que Goldsmith teve a intenção de transmitir a mesma mensagem que Isaacson, porém, de forma irônica. Na verdade, ele quis chamar atenção para a incrível habilidade que Einstein possuía para administrar o tempo. Isaacson revela uma das artimanhas utilizada pelo físico para conseguir se dedicar às pesquisas científicas. Na mesma carta ao amigo, Einstein narrou: "eu era capaz de realizar o trabalho de um dia inteiro em duas ou três horas. [...] No restante do dia, cuidava de minhas próprias ideias. [...] Sempre que alguém entrava, eu enfiava minhas anotações na gaveta da escrivaninha e fingia estar fazendo o serviço do escritório (ISAACSON, 2007, p. 96).

Nesse trabalho, Einstein realizava diariamente experimentos mentais para averiguar a aplicabilidade teórica ao experimento. Além disso, seu chefe, Friedrich Haller, era cético e dizia sempre para Einstein partir do pressuposto de que tudo o que o inventor escreveu estava errado. Isso forçava Einstein a questionar o conhecimento convencional e jamais aceitar uma verdade de algo só porque todos a consideram óbvia (ISAACSON, 2007). Esses princípios eram muito úteis para um físico teórico que iria questionar o tempo absoluto.

As respostas encontradas por Einstein para tal questionamento, mais tarde, tornar-se-iam as bases de sua teoria, publicada em 1905, a Relatividade Especial.

\section{A Relatividade Especial}

Goldsmith enfatiza, no capítulo da Relatividade Especial, o estudo matemático da teoria. Na verdade, ele utiliza diversos métodos com o intuito de facilitar a visão algébrica da conjectura. Sempre se valendo da linguagem cômica, explana a questão teórica da dilação do tempo e da contração das distâncias, por meio de figuras e exemplos bem consolidados entre os que compreendem, ao menos superficialmente, a teoria.

A retórica utilizada pelo autor procura dramatizar todo o enredo da descoberta. Douglas Allchin (2003) evidencia essa técnica como drama afetivo. Ela torna o texto persuasivo e aumenta sua credibilidade, torna-o mais aceitável pelo 
leitor. Além disso, os efeitos emotivos facilitam a memorização do texto. Allchin (2003) suspeita que essa seja uma das causas para a perpetuação dos mitos científicos.

Já Isaacson apresenta um contexto diferente. Inicia relatando que Galileu já havia previsto que as leis da mecânica eram válidas em qualquer referencial que se desloque com velocidade constante. Galileu queria defender a ideia copernicana de que a Terra "não está imóvel no centro do universo enquanto tudo gira em torno dela. Os céticos diziam que, se a Terra estivesse em movimento, como alegava Copérnico, perceberíamos" (2007, p. 125). Galileu refutou a hipótese cética com um experimento mental: poderíamos soltar alguns insetos dentro de uma cabine de um navio; na mesma cabine, pendurar uma garrafa que se esvazia gota a gota; as gotas caem numa bacia grande, cheia de água com peixes em seu interior. Galileu afirma que

os pequenos animais voam na mesma velocidade para todos os lados da cabine. Os peixes nadam indiferentemente em todas as direções. A gota caiu na bacia debaixo dela: e, quando você joga algo para seu amigo, não precisa jogar com mais força numa direção que na outra (ISAACSON, 2007, p. 126).

Logo após, o autor cria uma extensa narrativa que demonstra a visão newtoniana da luz como partícula, em contraste com a teoria de Maxwell, que encarava a luz como uma onda. Além disso, evidencia a influência causada por alguns físicos experimentais que desenvolveram várias tentativas fracassadas de provar a existência do éter. Com relação a esse fracasso, Einstein afirmou: foi a "primeira trilha que me levou ao que chamamos de princípio da relatividade especial" (ISAACSON, 2007, p. 133).

Goldsmith relata os mesmos acontecimentos, mas sem fazer uma ligação entre eles e o desenvolvimento da Teoria da Relatividade. São informações históricas valiosas ao leitor, mas não estão articuladas aos pensamentos de Einstein, que foi fortemente influenciado pelo contexto científico e filosófico da época.

Após a publicação da teoria da Relatividade Especial, Einstein passaria os próximos dez anos desenvolvendo as bases de uma teoria mais completa, a Relatividade Geral. 


\section{A Relatividade Geral}

A Relatividade Geral foi minuciosamente enunciada na obra de Isaacson. $\mathrm{O}$ autor inicia a narrativa expressando a inquietação de Einstein, que se deu conta de que a teoria da Relatividade Especial estava incompleta em pelo menos dois aspectos:

Em primeiro lugar, afirmava que nenhuma interação fisica poderia se propagar mais depressa que a velocidade da luz; isso conflitava com a teoria da gravidade de Newton, que concebia a gravidade como uma força que agia instantaneamente sobre objetos distantes. Em segundo lugar, aplicavase apenas ao movimento em velocidade constante. Por isso, nos dez anos seguintes, Einstein dedicou-se a um esforço articulado para apresentar uma nova teoria de campo da gravidade e generalizar sua teoria da relatividade, a fim de que fosse aplicada a movimento acelerado (ISAACSON, 2007, p. 205).

Tais aspectos também foram evidenciados por Goldsmith, porém, com menos detalhes. O autor justifica o nome "Especial" da Teoria da Relatividade pelo fato de que ela "só vale na situação especial em que você está se movendo uniformemente em linha reta, situação a que o Princípio da Relatividade se aplica" (GOLDSMITH, 2002, p. 101). Continua a narrativa enfatizando que Einstein "queria ampliar a teoria, de modo que ela pudesse valer para todos os movimentos, não apenas os uniformes" (Ibid.).

O primeiro avanço de Einstein em busca da teoria Geral ocorreu em 1907 (ISAACSON, 2007). Einstein criou um experimento mental em que especulava sobre o que um observador em queda livre sentiria. Tal experimento o levou a adotar o princípio de que "os efeitos locais de acelerar e estar num campo gravitacional eram impossíveis de distinguir" (p. 206). Esse é o princípio da equivalência, considerado por Einstein o pensamento mais feliz de sua vida (GOLDSMITH, 2002).

Na sequência das narrativas, podemos notar diferenças nos focos dos autores. Isaacson foca nos passos dados por Einstein durante o desenvolvimento da Teoria Geral da Relatividade. O autor relata o grande impasse sofrido pelo cientista quando se deparou com uma matemática que estava além da sua compreensão. Segundo Isaacson, "quando Einstein se mudou de Praga de volta para Zurique, em julho de 1912, uma das primeiras coisas que fez foi visitar o amigo Marcel Grossman, cujas anotações ele usava quando faltava às aulas de matemática na Politécnica de Zurique" (ISAACSON, 2007, p. 208). 
Einstein precisava "de um sistema matemático capaz de expressar - e talvez ajudá-lo a descobrir - as leis que governam o campo gravitacional" (ISAACSON, 2007, p. 209). Grossman se animou com as ideias de Einstein e juntos trabalharam exaustivamente até a publicação da Teoria Geral. Einstein se preocupava com questões filosóficas da teoria, além de "farejar os princípios físicos subjacentes da natureza" (Ibid.) e deixava para Grossman a tarefa de descobrir a melhor expressão matemática para esses princípios, fato registrado na história na carta de Einstein para o físico Arnold Sommerfeld:

Estou atualmente trabalhando só no problema gravitacional e creio que, com a ajuda do meu amigo matemático aqui, superarei todas as dificuldades. [...] Adquiri um respeito enorme pela matemática, cujos aspectos mais sutis até agora considerei, em minha ignorância, apenas um luxo! (ISAACSON, 2007, p. 209)

Einstein e Grossman publicaram um esboço de uma teoria alternativa, o qual chamaram de Entwurf. Nesse esboço, Einstein se deparou com alguns problemas. "Quanto mais refletia sobre o Entwurf, mais se dava conta de que as equações não atingiam o objetivo de serem genericamente ou mesmo amplamente covariantes" (ISAACSON, 2007, p. 215).

Além disso, após fazer inúmeros cálculos com Michele Besso, Einstein descobriu que o Entwurf não satisfazia o princípio de Mach, que contestou a noção de espaço absoluto enunciado por Newton e "argumentou que a inércia existia porque a água girava em relação ao restante da matéria existente no universo" (ISAACSON, 2007, p. 216), no famoso experimento do balde proposto por Newton.

Esses e outros problemas fizeram Einstein abandonar a teoria Entwurf no outono de 1915 (ISAACSON, 2007). Para substituir a teoria, o cientista mudou de foco, deixando de lado os princípios básicos da física e retomando a confiança na estratégia matemática.

Em um período de quatro semanas, quando apresentava uma sequência de palestras na Academia Prussiana, Einstein correu contra o tempo para apresentar sua teoria Geral da Relatividade, já que o físico David Hilbert estava prestes a publicar uma teoria semelhante ao Entwurf, mas com os devidos problemas encontrados por Einstein corrigidos.

No dia da última apresentação na Academia, 25 de novembro de 1915, Einstein apresentou o "conjunto de equações covariantes que coroaram a Relatividade Geral” (ISAACSON, 2007, p. 234). Antes disso, Einstein escreveu a Hilbert, de certa forma espantado, enunciando o quanto as duas teorias eram parecidas, mas 
destacando que já havia considerado as equações invariantes três anos atrás, quando trabalhava com seu amigo Grossman. Hilbert educadamente respondeu a correspondência:

Cordiais congratulações por conquistar o movimento do periélio. Se eu pudesse calcular com sua rapidez, em minhas equações o elétron teria de capitular e o átomo de hidrogênio teria de emitir uma nota de desculpas por não irradiar (Ibid.)

Isaacson, então, procurou descrever minuciosamente todo o contexto do desenvolvimento da teoria da Relatividade Geral.

Já Goldsmith focou em elementos explicativos, procurando tornar os conceitos físicos da teoria compreensíveis aos leitores. Para explicar o princípio da equivalência, por exemplo, o autor utilizou desenhos em que os personagens aparecem em situações engraçadas. Além disso, procurou esclarecer o princípio de maneira simples e direta: "se você está caindo, não pode sentir a gravidade" (GOLDSMITH, 2002, p. 103).

Utilizou os mesmos recursos para explicar a curvatura da luz:

Imagine que uma enorme bola peluda passa rolando a toda por você, em linha reta. Você tenta agarrá-la, segura firme alguns pelos, mas como não tem força para detê-la, ela se solta e segue em frente. O que acontece com sua direção? Desvia-se um pouquinho, tal como a luz quando passa pelo Sol. Mas não é só: você também reduz a velocidade da bola. A gravidade faz a mesma coisa com luz: ela a faz curvar-se e reduz sua velocidade. (GOLDSMITH, 2002, p. 108).

Goldsmith apresenta ao leitor alguns dos problemas que Einstein teve que enfrentar, principalmente os relacionados à matemática: "como é que o Beto podia então escolher a maneira certa de descrever como o espaço-tempo de fato se curva?" (GOLDSMITH, 2002, p. 115). No entanto, apresenta uma versão para a solução dos problemas completamente diferente das apresentadas por Isaacson:

Bem, o velho Newton ajudou muito no começo. Suas leis funcionavam magnificamente em quase todas as situações. Logo, as equações do Beto tinham de dar mais ou menos as mesmas respostas que as do Isaac, porque, para o mundo a que estamos acostumados, o Isaac estava para lá de quase certo!

É que as equações do Isaac só falharam num caso: o movimento do planeta Mercúrio. O Beto tinha de explicar tudo tão bem quanto o Isaac - e seria melhor ainda se também pudesse explicar o movimento de Mercúrio. 
Pelo menos o Beto sabia como checar as respostas que as suas equações do espaço-tempo davam, mas como podia saber que tipo de equação experimentar primeiro?

Foi aí que apareceu a ideia de "Deus". O Beto disse com seus botões que "Deus" teria escolhido as equações mais simples, então tentou as mais simples - e elas funcionaram! (GOLDSMITH, 2002, p. 116).

No trecho acima, fica clara a diferença entre as retóricas dos autores. Goldsmith, além de suprimir os detalhes, apresenta um fato que, sem dúvidas, não corresponde à realidade. Einstein, segundo Isaacson, trabalhou freneticamente durante quatro semanas para apresentar os resultados de suas pesquisas antes de Hilbert. Ele teve que abandonar uma teoria e apostar todas as fichas em outra, e não simplesmente escolher as equações mais simples. Se fez isso, certamente, foi em uma atitude de quase desespero.

Talvez esse seja o trecho do livro de Goldsmith mais idealizado segundo Allchin (2003), pois os detalhes foram suprimidos, as nuances que dariam qualidade ao texto se perderam e os extremos do contexto histórico emergiram e se destacaram. Como constatado anteriormente, aferimos maior crédito à obra de Isaacson, pois o autor fundamentou sua obra em manuscritos do próprio Einstein, além de cartas trocadas com amigos, cientistas e parentes.

\section{Algumas considerações}

Os livros de divulgação científica são de extrema importância para a popularização da ciência. Por meio deles, diminui-se a distância entre a ciência e a tecnologia (MARQUES et al., 2011), tão presente na vida cotidiana moderna.

No entanto, é possível que a informação contida nas obras de divulgação científica não esteja de acordo com o conhecimento das fontes primárias que originaram tais obras. Também é admissível que muitos dos detalhes que permitiriam uma visão mais ampla do conhecimento científico relatado sejam suprimidos, a fim de facilitar a compreensão do conteúdo pelo consumidor popular.

A retirada de tais detalhes acaba por caracterizar um aspecto na retórica do texto a qual Allchin chamou de idealização, em que a simplificação da narrativa acaba por reduzir "as múltiplas linhagens de pensamentos e ações, que caracteri- 
zam uma rede da história, em uma simples linha do tempo" (ALLCHIN, 2003, p. 344). Como demonstrado pelo autor e evidenciado na obra de Goldsmith, "as particularidades da descoberta - detalhes do tempo, lugar e cultura, contingências da personalidade, os acontecimentos biográficos, encontros ocasionais, etc. - tornamse secundários" "I (Ibid.) nas obras de divulgação científicas ditas idealizadas.

No entanto, Allchin afirma que a simplificação encontrada nos livros de divulgação científica é inevitável, mas os autores das obras e os professores que eventualmente as utilizam em sala de aula deveriam reconsiderar o poder e o impacto das narrativas idealizadas nos leitores e nos alunos. Os educadores recebem uma responsabilidade adicional, que deve ser articulada às abordagens que utilizam tais obras: a de perceber que os conceitos e as situações simplificados podem "mentir" (ALLCHIN, 2003).

Allchin (2003) assume, então, que não é possível erradicar a narrativa mítica de um texto. No entanto, existem algumas ferramentas para neutralizá-la. $\mathrm{O}$ autor deve suspeitar da simplicidade de um acontecimento; tomar cuidado com vinhetas clássicas; mesclar complexidade e controvérsia; descartar a linguagem romântica; não supervalorizar o cientista, apresentando-o como gênio; valorizar os feitos do pesquisador, não se esquecendo das devidas críticas; não apresentar a ciência como pronta, e, sim, como em processo de construção; apresentar os erros dos cientistas, explicando-os; nem sempre o método certo leva a conclusões exatas; muitas vezes o método certo conduz a conclusões erradas; apresentar a fonte do problema e a fonte da solução.

A comparação feita neste trabalho permitiu verificar que os dois autores elencaram praticamente os mesmos fatos históricos para permitir a compreensão do contexto da vida de Albert Einstein.

A diferença marcante entre os dois livros está na supressão de detalhes feita por Goldsmith. Não foi nenhuma surpresa constatar isso, já que podemos compreender que o leitor alvo talvez não se interessasse por tais detalhes, que deixariam a obra um pouco mais densa e exigiria maiores habilidades para uma boa interpretação. A linguagem utilizada por Goldsmith deixa claro que o seu objetivo é o de entreter o leitor e, ao mesmo tempo, apresentar-lhes um dos físicos

\footnotetext{
${ }^{4}$ The multiple lineages of thought and action that characterize a web of history are reduced to a single timeline.

${ }^{5}$ The particulars of the discovery - details of time, place and culture, contingencies of personality, biographical background, coincident meetings, etc. - become secondary.
} 
mais renomados da história da ciência em sua intimidade, evidenciando mais as qualidades do que os defeitos.

Esse tipo de retórica monumentaliza tanto o cientista quanto a sua obra. Allchin evidencia que a função desse artifício literário é o de "engajar o leitor" (ALLCHIN, 2003, p. 342). O cientista torna-se um super-humano, que exala virtudes, com um caráter exemplar, sem falhas, e suas descobertas acabam por serem consideradas atos heroicos (ALLCHIN, 2003). O método usado na ciência é inquestionável, pois a "estrutura mítica simplifica demasiadamente o processo" ${ }^{7}(\mathrm{p}$ $345)$.

Outro fator limitante, que restringiu Goldsmith, foi o comercial. O próprio autor, em um dado momento, quando narra o modo como Einstein dava aulas, relatou que o cientista havia dado uma bela explicação para o azul do céu. Porém, explicitou: "infelizmente, meu editor disse que este livro já está grande demais e que não dá para acrescentar outras páginas mostrando a explicação do Beto" (2002, p.87). Essa restrição obriga o autor a apresentar os fatos sem se ater aos detalhes, comprometendo a compreensão do contexto da vida de Einstein.

A idealização (ALLCHIN, 2003) do desenvolvimento da Teoria da Relatividade feita por Goldsmith, retirou-a do contexto histórico da época. A pesquisa feita por Einstein, os debates ocorridos, as consultas aos amigos cientistas, entre outros detalhes, não tiveram espaço na obra de Goldsmith. Após a leitura do livro, a impressão que fica é a de que nada estava ocorrendo paralelamente a esse acontecimento e que todo mérito deve ser dado à suposta genialidade de Einstein.

Goldsmith apresenta uma visão na qual Einstein é o gênio que desenvolveu teorias importantes se valendo exclusivamente da incrível inteligência e incomum habilidade para imaginar. Essa visão contribui para mistificar ainda mais a visão popular do cientista, que, trancado em seu gabinete, emprega grande esforço mental, sozinho, no anseio do momento "ahá", que culminará em uma grande descoberta.

De maneira diferente, Isaacson pôde se aprofundar nos detalhes da vida do físico e, assim, apresentou uma visão distinta da de Goldsmith. A forma como escreve sua obra, baseada em cartas pessoais do cientista, diários e anotações, evidencia uma genialidade diferente daquela concebida pela cultura popular. Isaacson mostra que Albert Einstein foi um gênio que associou ideias de outros gênios. $\mathrm{O}$ autor mostra que o físico foi profundamente influenciado por filósofos e cientis-

\footnotetext{
${ }^{6}$ Engage the reader.

${ }^{7}$ The mythic structure oversimplifies the process.
} 
tas que já haviam previsto os conceitos essenciais da Teoria da Relatividade Especial. Além disso, relata a falta de habilidade de Einstein com a matemática. Os auxílios de Mileva Maric e de Marcel Grossman, que mais tarde tornou-se seu matemático particular, foram fundamentais para o desenvolvimento das Teorias da Relatividade, Especial e Geral.

Entretanto, não podemos afirmar que a obra de Isaacson corresponde à real história da vida de Einstein. Como relatado anteriormente, retirar o aspecto mítico de uma obra de divulgação científica não é possível. Foi possível constatar, na obra desse autor, elementos que evidenciam tal mitificação, como a narrativa explicativa justificativa (ALLCHIN 2003), que apresenta a certeza da ciência, em que uma série de resultados poderia encadear uma descoberta científica.

No entanto, Isaacson, ao que parece, tomou cuidado com a retórica do seu texto, pois verificamos que o autor utilizou argumentos e técnicas para evitar mitificar sua narrativa. Isaacson empregou os mesmos critérios apresentados anteriormente na lista de Allchin para neutralizar a mitificação da ciência e do cientista na sua obra de divulgação científica. Dessa forma, a mensagem transmitida em seu livro não caracteriza o cientista como um super-humano; pelo contrário, mostra que a ciência se desenvolve por meio de aspectos relacionados ao contexto social do cientista.

É importante levar para a sala de aula essas considerações a respeito da ciência para que os alunos não a enxerguem como algo inalcançável. O intuito da divulgação científica é justamente o de tornar a ciência acessível aos cidadãos, mostrando que, por trás dela, existem muitos fatores que motivam o seu desenvolvimento, como objetivos políticos, sociais e tecnológicos, interesses comerciais, prêmios, ascensão acadêmica, entre outros. Muitas portas se abrem para um cientista que desenvolve uma pesquisa de profundo impacto social. Esse aspecto é bem evidenciado tanto na obra de Isaacson quanto na de Goldsmith, quando relatam que Einstein tinha muitas dificuldades para ser aceito na comunidade científica até publicar seus trabalhos no ano de 1905. A partir daí, o cientista passou a ser reconhecido pela comunidade e, assim, pôde dedicar-se exclusivamente à sua carreira científica.

No Brasil, o caminho à ciência é tão árduo quanto o percorrido por Einstein. No entanto, é possível que os nossos jovens percebam apenas as dificuldades relacionadas à matemática e ao desenvolvimento de teorias. A falta de oportunidades no mercado de trabalho, a difícil ascensão na carreira científica e a falta de financiamentos para as pesquisas talvez sejam desconhecidas pela maioria dos brasileiros. 
Então, levar a ciência real para a sala de aula é importante para que os interessados contribuam para a melhoria da atual situação. Nos últimos anos, tem-se observado um aumento considerável da inserção de conteúdos relacionados à história da ciência na escola básica (BARROS; CARVALHO, 1998). Defendemos a inserção de uma perspectiva histórica, assim como diversos autores da comunidade científica brasileira (MARTINS, A. F. P., 2008; MEDEIROS, 2009; PEDUZZI, 2008; SILVA et al., 2008; URIAS; ASSIS, 2011). Para Mathews (1994, p. 72 apud SILVA et al, 2008, p. 499), a História da Ciência pode

humanizar as ciências e aproximá-la mais dos interesses pessoais, éticos, culturais e politicos; tornar as aulas mais estimulantes e reflexivas, incrementando a capacidade do pensamento crítico; contribuir para uma compreensão maior dos conteúdos científicos, [...]; melhorar a formação dos professores contribuindo para o desenvolvimento de uma epistemologia da ciência mais rica e mais autêntica, isto é, a um melhor conhecimento da estrutura de ciência e seu lugar no marco intelectual das coisas.

Nessa perspectiva, o papel da história da ciência no ensino e da divulgação científica seria o de apresentar às pessoas a verdadeira ciência e como ela é realmente desenvolvida. Fica a cargo do professor apresentar aos alunos tal concepção de ciência, já que, na maioria dos livros de divulgação científica, ela é mitificada. Quanto menos idealizada for a ciência apresentada pelo professor, mais significativo será o serviço de apresentação dos detalhes do processo científico. Quanto menos a figura do cientista for monumentalizada, maior número de alunos poderá ser inspirado à carreira científica (ALLCHIN, 2003).

\section{Agradecimentos}

Agradecemos ao professor Dr. João José Caluzi por sugerir a leitura do texto de Allchin (2003) e utilizá-lo como referência bibliográfica neste trabalho.

\section{Referências bibliográficas}

ALLCHIN, D. Scientific myth-conceptions. Science Education, v. 87, n. 3, p. 329-351, 2003.

BACHELARD, G. A formação do espírito científico: contribuição para uma psicanálise do conhecimento. Tradução: Estela Dos Santos Abreu. Rio de Janeiro: Contraponto, 1996. 
BARROS, M. A.; CARVALHO, A. M. P. A história da ciência iluminando o ensino de visão. Revista Ciência \& Educação, v. 5, n. 1, p. 83-94, 1998.

GOLDSMITH, M. Albert Einstein e seu universo inflável. Tradução: Eduardo Brandão. 1. ed. São Paulo: Companhia das Letras, 2002.

HOLTON, G. Thematic origins of scientific thought. Kepler to Einstein. Cambridge: Harvard University Press, v. 1, 1973.

ISAACSON, W. Einstein - sua vida, seu universo. Tradução: Celso Nogueira; Denise Pessoa; Fernanda Ravagnani; Isa Mara Lando. 2. ed. São Paulo: Companhia das Letras, 2007.

MARQUES, A. L. F.; MOREIRA, C. C.; OLIVEIRA, D. G. DE; SANTOS, P. M. DOS. Disciplina de divulgação científica em curso de licenciatura em física. In: SIMPÓSIO NACIONAL DO ENSINO DE FÍSICA, XIX, 2011, Manaus. Atas...

MARTINS, A. F. P. História e Filosofia da Ciência no ensino: há muitas pedras nesse caminho... Caderno Brasileiro de Ensino de Física, v. 24, n. 1, p. 112-131, 2008 .

MARTINS, R. A. Como distorcer a física: considerações sobre um exemplo de divulgação científica 1 - Física clássica. Caderno Brasileiro de Ensino de Física, v. 15 , n. 3 , p. $243-264,2008$.

MEDEIROS, A. Entrevista com Conde Rumford: da teoria do calórico ao calor como uma forma de movimento. Física na Escola, v. 10, n. 1, p. 4-16, 2009.

PEDUZZI, L. Do átomo grego ao átomo de Bohr [S.1.]: Universidade Federal de Santa Catarina (publicação interna), 2008.

SILVA, C. P.; FIGUEIRÔA, S. F. M.; NEWERLA, V. B.; MENDES, M. I. P. Subsídios para o uso da História das Ciências no ensino: exemplos extraídos das geociências. Ciência \& Educação, v. 14, n. 3, p. 497-517, 2008.

URIAS, G.; ASSIS, A. A história da ciência no estudo da estrutura da matéria: uma avaliação dos alunos. In: SIMPÓSIO NACIONAL DO ENSINO DE FÍSICA, XIX, 2011, Manaus. Atas...

VIEIRA, C. L. Pequeno manual de divulgação científica: um resumo. Guia de divulgação científica, p. 13-14, 2004. 